\title{
Lepiotoid Agaricaceae (Basidiomycota) from São Camilo State Park, Paraná State, Brazil
}

\section{Ferreira $\mathrm{AJ}^{1^{*}}$ and Cortez $\mathrm{VG}^{1}$}

${ }^{1}$ Universidade Federal do Paraná, Rua Pioneiro 2153, Jardim Dallas, 85950-000, Palotina, PR, Brazil

Ferreira AJ, Cortez VG 2012 - Lepiotoid Agaricaceae (Basidiomycota) from São Camilo State Park, Paraná State, Brazil. Mycosphere 3(6), 962-976, Doi 10.5943 /mycosphere/3/6/11

A macromycete survey at the São Camilo State Park, a seasonal semideciduous forest fragment in Southern Brazil, State of Paraná, was undertaken. Six lepiotoid fungi were identified: Lepiota elaiophylla, Leucoagaricus lilaceus, L. rubrotinctus, Leucocoprinus cretaceus, Macrolepiota colombiana and Rugosospora pseudorubiginosa. Detailed descriptions and illustrations are presented for all species, as well as a brief discussion on their taxonomy and geographical distribution. Macrolepiota colombiana is reported for the first time in Brazil and Leucoagaricus rubrotinctus is a new record from the State of Paraná.

Key words - Agaricales - Brazilian mycobiota - new records

\section{Article Information}

Received 30 October 2012

Accepted 14 November 2012

Published online 3 December 2012

*Corresponding author: Ana Júlia Ferreira - e-mail: anaj.bio@ gmail.com

\section{Introduction}

Agaricaceae Chevall. (Basidiomycota) comprises the impressive number of 1340 species, classified in 85 agaricoid, gasteroid and secotioid genera (Kirk et al. 2008), and grouped in ten clades (Vellinga 2004). The family is of great economic and medical importance because several of its members are edible, medicinal or poisonous mushrooms (Didukh et al. 2003), and obviously of high ecological relevance due to occurrence in several environments. The agaricoid members are characterized by the free gills, with a regular and non-gelatinized trama, composed of filamentous hyphae, and basidiospores that are hyaline, pale pink or yellow to green, brown and black (Vellinga 2004).

In Brazil, pioneers on the study of such fungi were European naturalists, e.g. J.P.F.C. Montagne, M.J. Berkeley and C.L. Spegazzini, who visited and/or studied collections from the country in the $19^{\text {th }}$ century. More recently, researchers have studied agaricoid diversity in the Northeast (Wartchow et al. 2008), Southeast (Capelari \& Gimenes 2004, Albuquerque et al. 2010) and South (Rother \& Silveira 2008, 2009a, 2009b). From the State of Paraná, Meijer $(2006,2010)$ listed 62 agaricoid taxa belonging to Agaricus (17), Chlorophyllum (2), Coprinus (1), Cystolepiota (3), Hymenagaricus (2), Lepiota (18), Leucoagaricus (6), Leucocoprinus (5), Macrolepiota (3), Melanophyllum (2), Micropsalliota (2), and Rugosospora (1). His studies, however, were focused on the mycobiota from the eastern region of the State, where distinct vegetation types occur: the mixed (with Araucaria angustifolia) and dense ombrophilous forests (Meijer 2006), in contrast to seasonal semideciduous forest that occurs in 


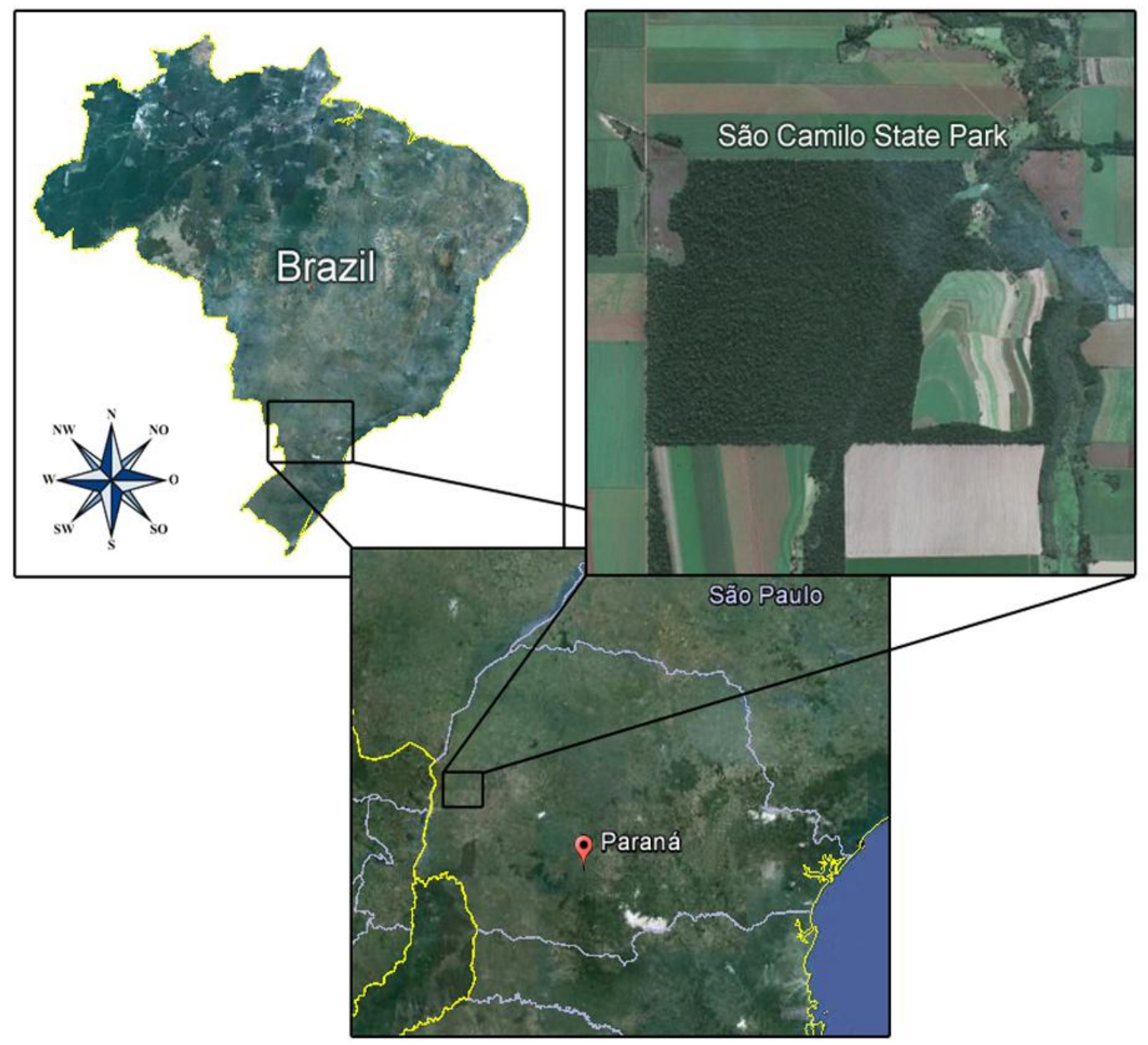

Fig. 1 - Location of São Camilo State Park, in Southern Brazil.

the western region. Aiming to provide additional data on the mycobiota from the western region of Paraná State, a macromycete survey was proposed and in the present paper data on the lepiotoid agarics are presented.

\section{Methods}

Fieldwork was conducted from August 2011 and June 2012 in the São Camilo State Park (abbreviated as PESC), situated in the municipality of Palotina, western region of

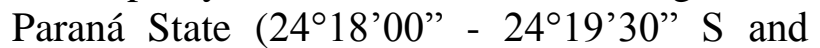

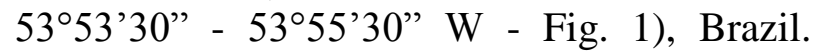
Collected specimens from May 2010 to July 2011 at PESC were also considered. PESC comprises an area of 387 ha, placed in the domain of the Atlantic rain forest, with a seasonal semideciduous forest vegetation and a Cfa (subtropical humid) climate according to the Köppen's classification (IAP, 2006).
All specimens were analyzed both macro-and micromorphologically following standard procedures (Largent 1977, Largent et al. 1986). Colour names and codes used in the macroscopical descriptions are according to Kornerup \& Wanscher (1978). Free-hand sections were mounted in $3 \% \mathrm{KOH}$ preparations, as well as Congo red, Melzer and cresyl blue. Measurements and micrographs were taken with digital camera integrated to a Motic BA310 optical microscope, through the Motic Image Plus 1.0 software. Scanning electron microscopy (SEM) analysis was performed at the Center of Electron Microscopy of the Universidade Federal do Paraná, Curitiba, Brazil. All specimens were dried in an open air drier $\left( \pm 40^{\circ} \mathrm{C}\right)$ and are preserved at the mycological collection of the Campus Palotina, Universidade Federal do Paraná (HCP). 
Mycosphere Doi 10.5943/mycosphere/3/6/11
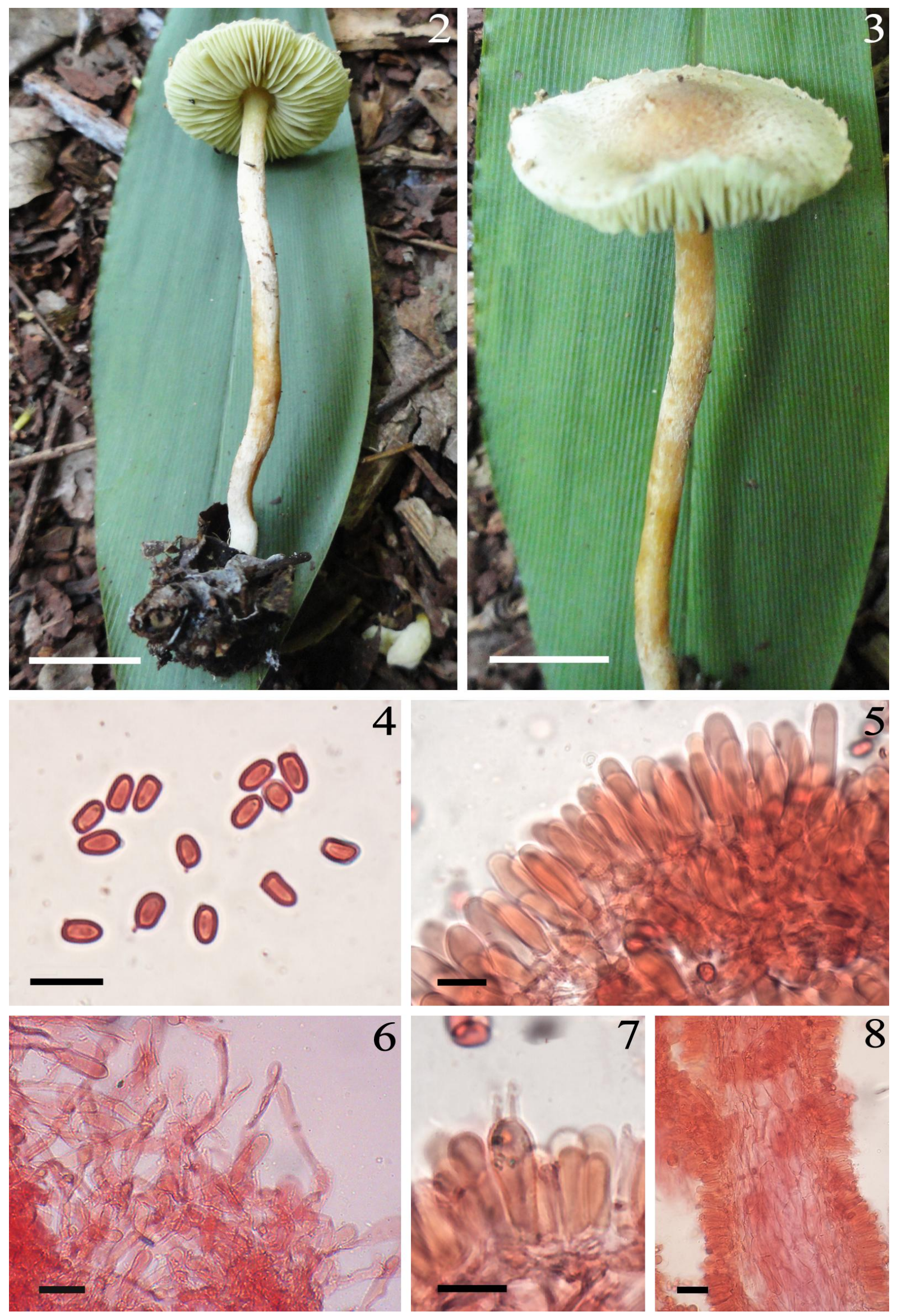

Figs 2-8 - Lepiota elaiophylla. 2,3 Basidioma. 4 Basidiospores. 5 Cheilocystidia. 6 Pileus covering hyphae. 7 Basidium. 8 Lamella trama. - Bars: $2=10 \mathrm{~mm} ; \mathbf{3}=5 \mathrm{~mm} ; \mathbf{4 , 5}, 7=10 \mu \mathrm{m} ; \mathbf{6}, \mathbf{8}=20 \mu \mathrm{m}$. 


\section{Taxonomy}

Six species of lepiotoid agarics are recorded. Descriptions and illustrations are presented for each, followed by a brief taxonomic and geographical discussion.

Lepiota elaiophylla Vellinga \& Huijser, Boll. Gr. Micol. G. Bres. 40: 462 (1998) Fig 2-8

Basidioma solitary, on litter in the forest. Pileus $16 \mathrm{~mm}$, convex, yellowish brown (5E4) on the disc, to pale orange (5A3) towards the margin, surface covered by numerous and small yellowish brown (5E4) scales, radially dispersed towards the margin, which is smooth, but appendiculate with velar remnants, context fleshy, $1 \mathrm{~mm}$ near the stipe insertion, to 0.8 $\mathrm{mm}$ in the middle of lamellae, pale orange (1A3). Lamellae free, close and with lamellulae, greyish yellow (1B4), margin entire and concolour with sides, $1.5 \mathrm{~mm}$ diam. Stipe $44 \times 1.8 \mathrm{~mm}$, central, cylindrical, greyish yellow (1B3) in the apex, to pale grey (1B1) downwards, surface fibrillose, dry, with scattered basal rhizomorphs, context yellowish white (1A2), fibrous, $0.5 \mathrm{~mm}$ thickness. Veil present only on pileus margin, as appendiculate, membranous and pale orange (1A3) remnants. Spore print not checked.

Basidiospores (5.2-)5.4-7(-7.5) × 2.5$4.3 \mu \mathrm{m}, \mathrm{Q}=1.6-2.2(-2.5), \mathrm{Qm}=1.8$, ellipsoid, oblong-ellipsoid to slightly stenosporic, with a lateral apiculus, walls smooth and little thickened $(0.5-0.9 \mu \mathrm{m})$, without a germ pore, hyaline, metachromatic and dextrinoid. Basidia 15.1-22.5 × 5.7-7.6 $\mu \mathrm{m}$, clavate, hyaline, tetrasporic, with sterigmata $2.5-4.1 \mu \mathrm{m}$ long. Cheilocystidia 17.8-33.7 $\times$ 4.8-11.3 $\mu \mathrm{m}$, clavate to lageniform, hyaline, smooth and thin-walled, numerous in the lamella edge. Pleurocystidia absent. Lamella trama subregular, composed of hyaline and thinwalled hyphae, 3.2-12.8 $\mu \mathrm{m}$ diam., sometimes clamped. Pileus covering a trichoderm, composed of pale yellowish brown hyphae, 3$10.2 \mu \mathrm{m}$, with slightly thickened walls, clamped, the terminal elements sometimes flexuous, cylindrical-subclavate, non-septate, 24.3-80.1 × 5.1-12.4 $\mu \mathrm{m}$. Clamp connections present.

Known distribution - Asia (Sysouphanthong et al. 2011), Europe (Holec \& Hálek 2008) and Brazil (Wartchow et al. 2008).
Material examined - Brazil, Paraná State, Palotina, PESC, 9 November 2011, leg. RL Dias 28-3 (HCP).

Notes - This species is macroscopically similar to Lepiota xanthophylla P.D. Orton, but differs in the structure of the pileus covering, which is composed of shorter clavate hyphae, lageniform to utriform cheilocystidia, and more lemon-yellow to olive colours of basidioma (Holec \& Hálek 2008, Vellinga \& Huijser 1997). Although morphologically similar, Vellinga (2001b) showed that L. elaiophylla belongs to another clade in Lepiota, including $L$. subincarnata J.E. Lange and $L$. brunneoincarnata Chodat \& Martín, all those toxic species of agarics, containing amanitin (Vellinga 2003). According to Wartchow et al. (2008), other Neotropical species with yellow lamellae and clamped hyphae are similar to $L$. elaiophylla, as follows: L. parvispora Dennis from Venezuela (Dennis 1961), L. flavidocana Pegler from Lesser Antilles (Pegler 1983) and L. xanthophylloides Singer from the State of Pará, in northern Brazil (Singer 1973, as L. xanthophylla), but all these have basidiospores less than $6 \mu \mathrm{m}$ long. In Europe, L. elaiophylla is known from several countries, but certainly it is an adventitia species, as its records are from greenhouses and botanical gardens, strongly suggesting its recent introduction in the continent (Holec \& Hálek 2008, Gubitz 2011). The present collection is the third report for the species from Brazil, where it was reported from the States of Paraná (Meijer 2006) and Pernambuco (Wartchow et al. 2008). It is possible that the fungus has a South American origin and later was introduced to Europe.

Leucoagaricus lilaceus Singer, Lilloa 25: 274 (1952) '1951'

Figs 9-13

Basidiomata solitary or in pairs, on litter or wood under advanced stage of decomposition. Pileus 27-70 $\mathrm{mm}$ diam., convex to plano-convex, slightly umbonate, surface densely fibrillose, greyish brown (7E3) to violet brown (11E5) at the disc/umbo, then becoming gradually brown (6E4), greyish brown (11D3) to finally greyish red (11D4) towards the margin, over a white (1A1) background, margin smooth with small velar remnants; context fleshy, about $4 \mathrm{~mm}$ thickness 

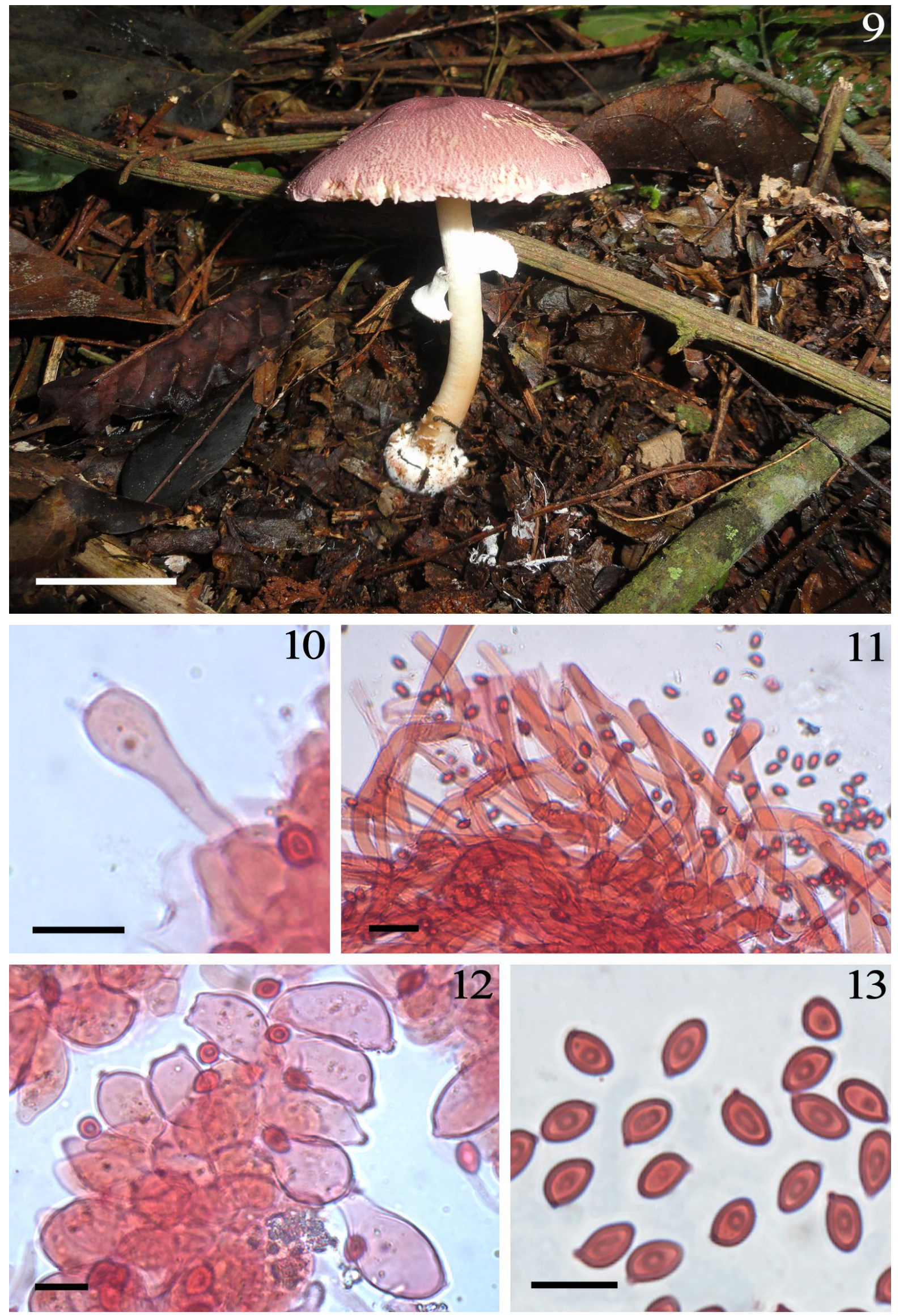

Figs 9-13 - Leucoagaricus lilaceus. 9 Basidioma. 10 Basidium. 11 Pileus covering hyphae. 12 Cheilocystidia. 13 Basidiospores. - Bars: $9=20 \mathrm{~mm} ; \mathbf{1 0 , 1 2 , 1 3}=10 \mu \mathrm{m} ; \mathbf{1 1}=20 \mu \mathrm{m}$. 
near the stipe insertion and 1-2 mm thickness in the medial portion of the pileus, white (1A1). Lamellae free, close and with lamellulae, margin entire, ca. $1 \mathrm{~mm}$ diam., yellowish white (1A2) with pinkish tones, concolour. Stipe 44-75 × 2.5-6 mm, central, tapered from base to apex, base strongly and abruptly bulbous reaching $12 \mathrm{~mm}$ diam.; surface dry, fibrillose, white (1A1) to yellowish white (1A2), context white (1A1) and fibrous, rhizomorphs scattered. Partial veil forming a membranous annulus on stipe apex, ascending, non-mobile, white (1A1) with a greyish brown (11D3) margin.

Basidiospores 6.1-7.3(-8.9) $\times$ 3.8-4.5 $\mu \mathrm{m}, \mathrm{Q}=1.4-1.8(-2.3), \quad \mathrm{Qm}=1,6, \quad$ ovoid to elliptical, with a distinct apiculus, hyaline, with smooth and thickened $(0.5-1 \mu \mathrm{m}$ diam.) walls, germ pore absent, metachromatic and dextrinoid. Basidia 15.4-23.4 × 6.2-9 $\mu \mathrm{m}$, clavate, hyaline, tetrasporic, with sterigmata 1.5-4.4 $\mu \mathrm{m}$ long. Cheilocystidia 22.8-32($36.3) \times 11-16.4 \mu \mathrm{m}$, ventricose, pyriform to clavate, the apex ranging from shortly rostrate to capitate, sometimes with a refractive apical drop, hyaline, smooth and thin walled, very numerous and crowded in the gill edge. Pleurocystidia absent. Lamella trama subregular, composed of hyaline, non-clamped, thin-walled hyphae, 4-17.5 $\mu \mathrm{m}$ diam. Pileus covering trichodermial, formed of erect, hyaline and smooth-walled hyphae, the terminal elements $24.1-87.9(-133.6) \times 5.1-$ $12.1 \mu \mathrm{m}$. Clamp connections absent.

Known distribution - subtropical South America: northern Argentina (Singer \& Digilio 1951) and southern Brazil (Meijer 2006, Rother \& Silveira 2009a).

Material examined - Brazil, Paraná State, Palotina, PESC, 24 March 2011, leg. AJ Ferreira \& RL Dias 21-21 (HCP); 23 October 2011, leg. AJ Ferreira \& RL Dias 23-10 (HCP); 10 April 2012, leg. AJ Ferreira \& VG Cortez 32-1 (HCP); 23 April 2012, leg. VG Cortez 346 (HCP).

Notes - This species belongs to Leucoagaricus Sect. Piloselli (Kühner) Singer and is macroscopically diagnosed by the pinkish lilac brown to purplish pileus, abruptly bulbous stipe base and slightly pinkish gills (Rother \& Silveira 2009a). Leucoagaricus lilaceus was originally described from
Tucumán (Argentina) and, in contrast to original diagnosis (Singer \& Digilio 1951), the current specimens have slightly larger basidiospores $(5.8-6.5 \times 4.3-4.8 \mu \mathrm{m})$ and pileus covering hyphae $(25-63 \times 8.8-13.2 \mu \mathrm{m})$. However, our results are in full agreement with type study and recently collected material by Rother \& Silveira (2009a) from Rio Grande do Sul State. The species is reported for the first time from the western Paraná State.

Leucoagaricus rubrotinctus (Peck) Singer, Sydowia 2: 36 (1948)

Figs 14-19

Basidioma solitary, on forest litter. Pileus $30 \mathrm{~mm}$ diam., plano-convex, umbonate, surface fibrillose, brown (6E5) at the disc/umbo and the radially arranged fibrils light brown (6D5), margin entire slightly smooth (without fibrils), context white (1A1), fleshy, about $1 \mathrm{~mm}$ near the stipe insertion to $0.5 \mathrm{~mm}$ at medial portion of gills. Lamellae free to remote, close, with lamellulae, yellowish white (2A2), margin entire and concolour with sides. Stipe $38 \times 3.5 \mathrm{~mm}$, yellowish white $(2 \mathrm{~A} 2)$, central, clavate, with a bulbous expanded (7 $\mathrm{mm}$ ) base, bearing scattered rhizomorphs, surface fibrillose and dry, fistulous, context fibrous, $0.5-1.5 \mathrm{~mm}$ thickness, white (1A1). Partial veil forming a membranous annulus in the medial portion of stipe, ascending, nonmobile, yellowish white (2A2) with a conspicuously discolor, light brown (6D5). Spore print not checked.

Basidiospores 6.7-8.8 × 4.3-5.8 $\mu \mathrm{m}$, $\mathrm{Q}=1.2-1.8, \mathrm{Qm}=1.4$, ovoid to ellipsoid, with a conspicuous apiculus, hyaline, wall smooth and somewhat thickened $(1 \mu \mathrm{m})$, without a germ pore, metachromatic and dextrinoid. Basidia 21-33 × 8-10 $\mu \mathrm{m}$, clavate, hyaline, thinwalled, bearing four, $2-5 \mu \mathrm{m}$ long sterigmata. Cheilocystidia 26-43.5 $\times 8-13 \mu \mathrm{m}$, fusoid, fusoid-clavate to lageniform, hyaline, smooth and thin-walled. Pleurocystidia absent. Lamella trama subregular, composed by hyaline and thin-walled hyphae, 3-17 $\mu \mathrm{m}$ diam. Pileus covering formed of a cutis of prostrate, filamentous, cylindrical hyphae, 3.4-10.5 $\mu \mathrm{m}$ diam., with a slight pale brown pigment, walls thin and smooth. Clamp connections absent.

Known distribution - Americas, Europe and Asia (Rother \& Silveira 2008, Kumar \& Manimohan 2009). 
Mycosphere Doi 10.5943/mycosphere/3/6/11
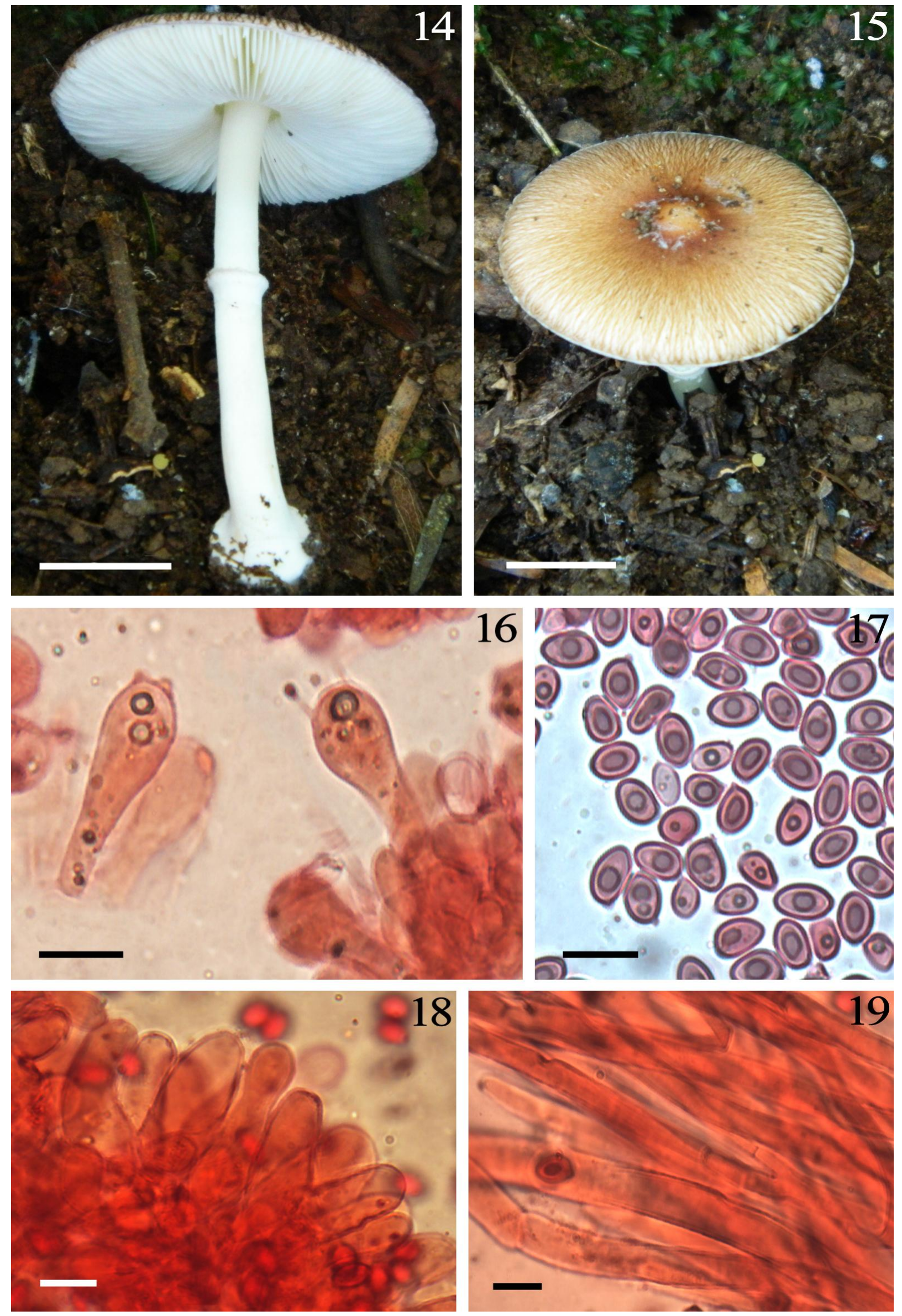

Figs 14-19 - Leucoagaricus rubrotinctus. 14, 15 Basidioma. 16 Basidia. 17 Basidiospores. 18 Cheilocystidia. 19 Pileus covering hyphae. - Bars: 14, $15=10 \mathrm{~mm} ; \mathbf{1 6}-\mathbf{1 9}=10 \mu \mathrm{m}$. 
Material examined - Brazil, Paraná State, Palotina, PESC, 15 May 2012, leg. VG Cortez 35-1 (HCP).

Notes - This species is diagnosed by the reddish colour of the pileus, which can range from orange to brown, according to developmental stage and it is the type of Leucoagaricus Sect. Rubrotincti Singer, which includes mushrooms with pigmented pileus and smooth basidiospores, with inconspicuous or absent germ pore. Franco-Molano et al. (2000) reported this species as possibly toxic. Lepiota rubrotinctoides Murrill seems to be close, but differs from $L$. rubrotinctus by virtue of smaller basidiospores $(7 \times 3.5 \mu \mathrm{m})$, lack of pileal scales and larger basidiomata (Murrill 1912). Leucoagaricus glabridiscus (Sundb.) Wuilb. is another related species, but it is a smaller and fragile mushroom, with a double layer of interwoven hyphae forming the pileus covering (Kumar \& Manimohan 2009). This fungus is identified according to FrancoMolano et al. (2000), however, it is possible that South American specimens identified under this name can be segregated in distinct taxa when a revision of Neotropical species is made. In Brazil, L. rubrotinctus was reported from the regions South (Rother \& Silveira 2008), Southeast (Rosa \& Capelari 2009) and North (Capelari \& Maziero 1988, as Lepiota rubrotincta). The studied specimens are the first record for the species from the State of Paraná.

Leucocoprinus cretaceus (Bull.) Locq., Bull. Mens. Soc. Linn. Lyon 14: 93 (1945) Figs 20-24

Basidiomata solitary to gregarious, on fallen trunks or advanced decomposed wood. Pileus 50-60 mm diam., campanulate when young to convex and umbonate then applanate at maturity, surface white (1A1), fully floccose over a smooth ground, except in the margin, which is distinctly sulcate-striate, disc more coloured, yellowish white (1A2), context fleshy, white (1A1), about $1 \mathrm{~mm}$ thickness near the stipe insertion to $<0.5 \mathrm{~mm}$ in the medial portion of lamellae. Lamellae free, close, with lamellulae of several lengths, $<3.5 \mathrm{~mm}$ diam., white (1A1) from young to mature stages, margin entire, concolour. Stipe 6-80 $\times 4 \mathrm{~mm}$, central, clavate to sub-bulbous, the base reaching $12 \mathrm{~mm}$ diam., white (1A1) to yellowish white (1A2), becoming greyish yellow (4B5) after handling, surface entirely floccose to fibrillose, especially from basal half of stipe length, rhizomorphs absent, context fibrous, white (1A1). Partial veil forming a fragile and easily detachable membranous annulus, delicate, medial to apically positioned, simple and mobile, white (1A1), which can be absent (lost) in some specimens due to its fragility. Spore print white.

Basidiospores 7.7-10.7 × 5.5-6.8 $\mu \mathrm{m}$, $\mathrm{Q}=1.4-1.7, \mathrm{Qm}=1.5$, ellipsoid to ovoid, with an apiculus, walls hyaline, smooth and thickened (0.7-1.1 $\mu \mathrm{m}$ diam.) with a slightly truncate germ pore and covered by a hyaline cap, metachromatic and dextrinoid. Basidia 17.0 $25.9 \times 8.1-11.5 \mu \mathrm{m}$, clavate, hyaline, thinwalled, bearing four sterigmata, 1.5-3.9 $\mu \mathrm{m}$ long. Cheilocystidia 22.9-55.9 × 6.8-13.4 $\mu \mathrm{m}$, clavate, cylindro-clavate or fusoid, some with a capitate or mucronate-rostrate apex, hyaline, smooth and thin-walled. Pleurocystidia absent. Lamella trama subregular, formed by hyaline, thin-walled hyphae, 3.9-17 $\mu \mathrm{m}$ diam. Pileus covering is a cutis, composed of a layer prostrate hyphae, 2.1-8.9 $\mu \mathrm{m}$ diam., hyaline, smooth and thin-walled. Clamp connections absent.

Known distribution - pantropical (Rother \& Silveira 2009b).

Material examined - Brazil, Paraná State, Palotina, PESC, 27 January 2011, leg. AJ Ferreira \& RL Dias 17-44 (HCP); 16 February 2011, leg. AJ Ferreira \& RL Dias 18-20 and 18-45 (HCP); 17 April 2012, leg. VG Cortez \& RL Dias 33-1(HCP); 23 April 2012, leg. VG Cortez 34-4 (HCP).

Notes - The entirely white and floccose pileus and stipe surface, which are very fragile and easily fall away with handling, are features that allow field identification (Candusso \& Lanzoni 1990, Vellinga 2001a). Microscopically, the spores present a conspicuous germ pore with a hyaline cap and pileus covering formed of cylindrical hyphae (Kumar \& Manimohan 2009). Leucocoprinus squamulosus (Mont.) Pegler, with non-inflated stipe, and L. cepistipes (Sow.) Pat. with brownish scales in the center of pileus are the most similar taxa (Wartchow et al. 2008, Rother \& Silveira 2009b). In Europe, L. 
Mycosphere Doi 10.5943/mycosphere/3/6/11
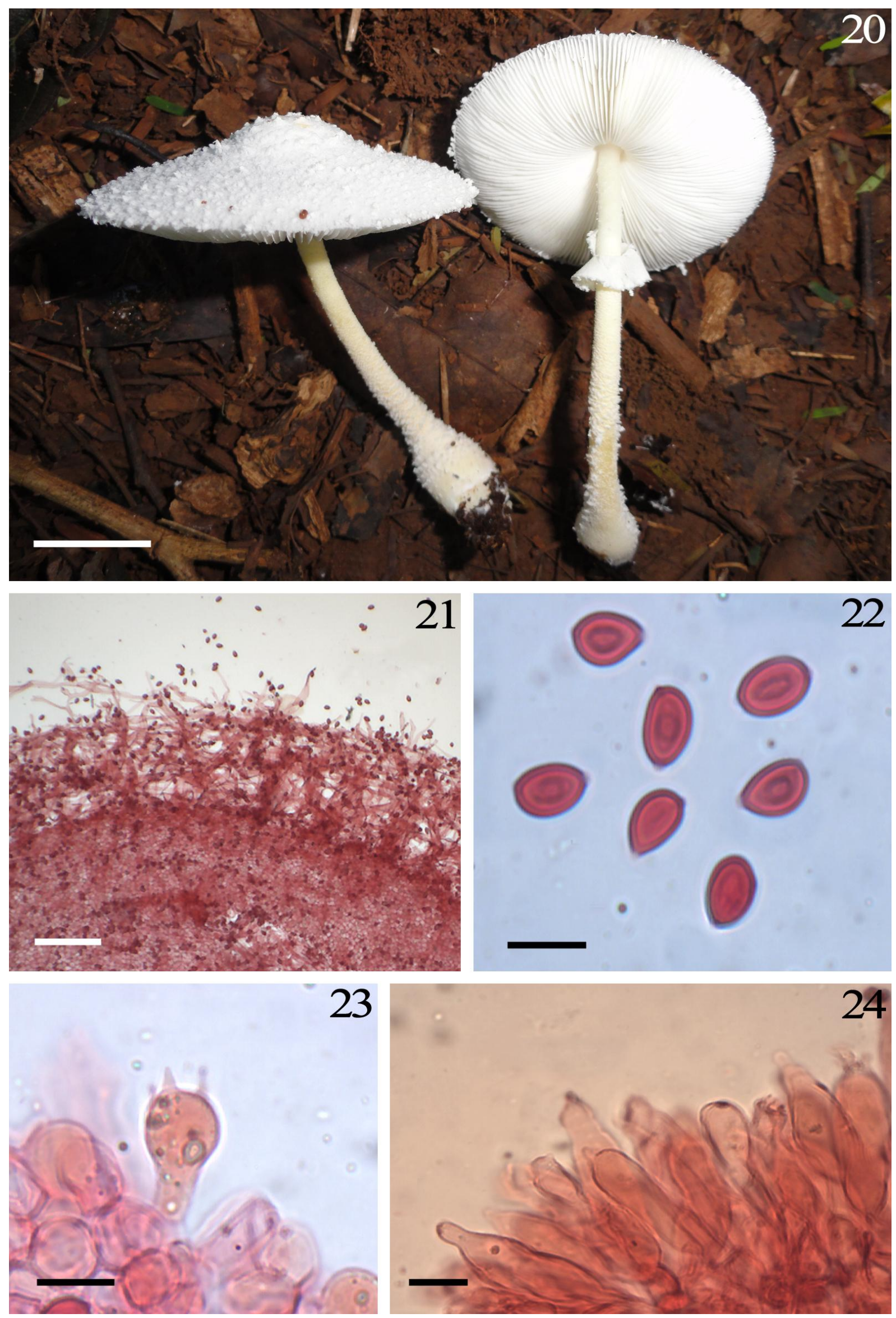

Figs 20-24 - Leucocoprinus cretaceus. 20 Basidiomata. 21 Pileus covering hyphae. 22 Basidiospores. 23 Basidium. 24 Cheilocystidia. - Bars: $20=20$ mm; $21=100 \mu \mathrm{m} ; \mathbf{2 2}-\mathbf{2 4}=10 \mu \mathrm{m}$. 
Mycosphere Doi 10.5943/mycosphere/3/6/11
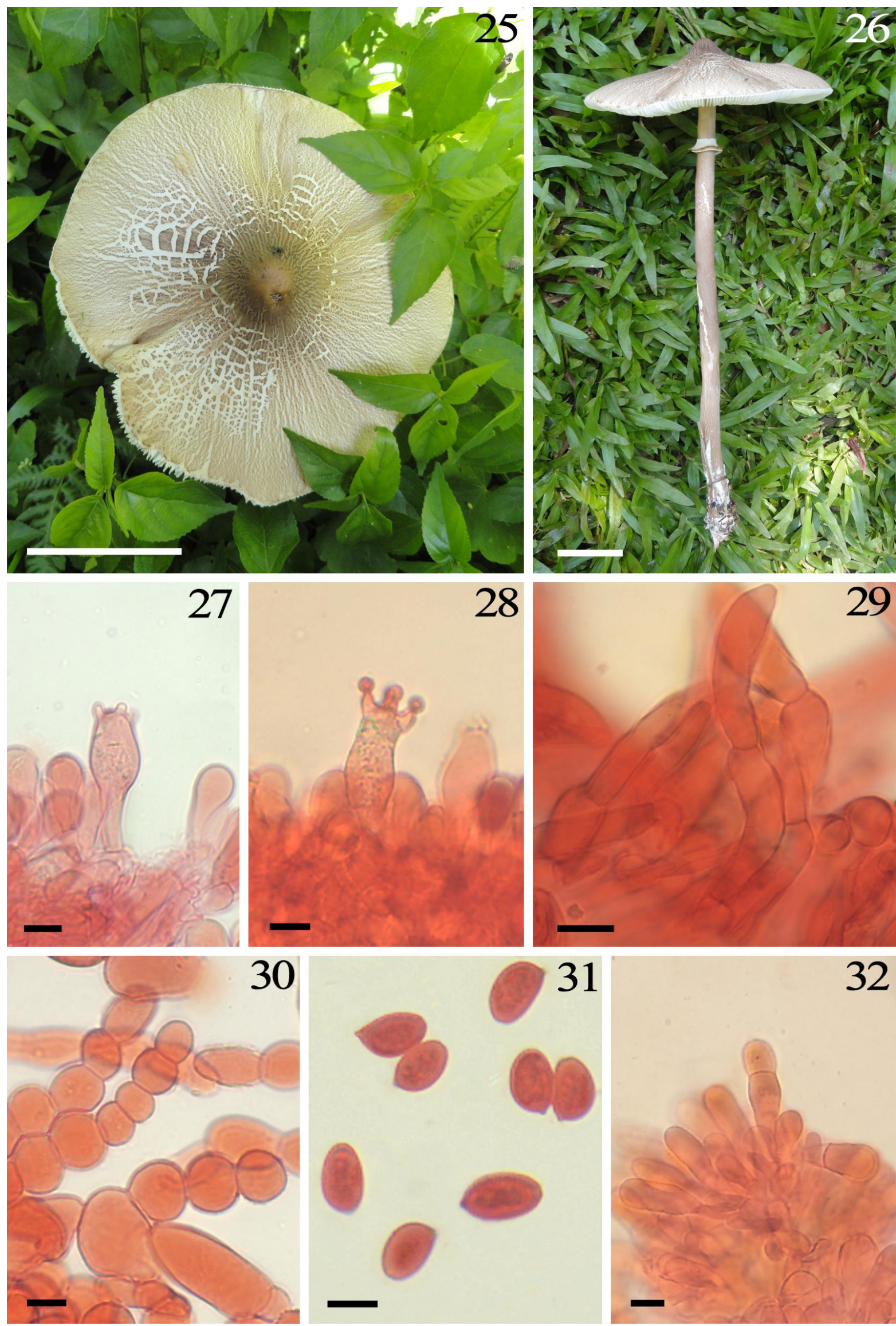

Figs 25-32 - Macrolepiota colombiana. 25, 26 Basidiomata. 27, 28 Basidia. 29 Caulocystidia. 30 Pileus covering. 31 Basidiospores. 32 Cheilocystidia. - Bars: 25, 26 =50 mm; 27-32 = $10 \mu \mathrm{m}$. 
cretaceus is considered one of the most common lepiotoid fungi and one of the largest ( $\leq 100 \mathrm{~mm}$ diam. - Candusso \& Lanzoni 1990). The mushroom is also common in Brazil, where it has been recorded from the States of Pernambuco (Wartchow et al. 2008), Rio Grande do Sul (Sobestiansky 2005, Rother \& Silveira 2009b) and Paraná; in the latter, Meijer (2006) reported it in several localities, including the Iguaçu National Park, in the western region of the State.

Macrolepiota colombiana Franco-Molano, Actual. Biol. 21: 14 (1999) Figs 25-32

Basidiomata solitary or in pairs among herbaceous vegetation, in forest edge. Pileus 120-141 mm diam., 39-60 mm high, planoconvex, umbonate, surface dry, areolate, yellowish brown (5F8) at the disc and umbo, to fibrillose and yellowish brown (5E5) towards the margin, which is finally smooth and orange white (5A2), context fleshy, white (1A1), 1.5 $\mathrm{mm}$ thickness near stipe insertion to $4 \mathrm{~mm}$ in the medial portion of lamellae. Lamellae free, close, with lamellulae, margin entire, $<7 \mathrm{~mm}$ diam., orange white (5A2), the edge concolour with sides. Stipe $220-311 \times 8-10 \mathrm{~mm}$, central, cylindrical and expanded, slightly sub-bulbous, yellowish brown (5F6) to dark blond (5D4) above, surface fibrillose, opaque, base with scattered rhizomorphs of same colour, fistulous, context fibrous, $<5 \mathrm{~mm}$ thickness, white (1A1). Partial veil producing an apical and membranous annulus, simple and mobile, orange white (5A2), with a distinct margin, yellowish brown (5F4) to greyish brown (5D3). Spore print not checked.

Basidiospores $12-17 \times 8-10 \mu \mathrm{m}$, $\mathrm{Q}=1.2-1.9, \mathrm{Qm}=1.6$, ellipsoid, with a broad and hyaline germ pore, wall smooth and $<1$ $\mathrm{mm}$ thick, metachromatic and dextrinoid. Basidia 29-42(-47) $\times 10-17 \mu \mathrm{m}$, clavate, thinwalled, tetrasporic, with sterigmata $2.5-6 \mu \mathrm{m}$ long. Pleurocystidia absent. Cheilocystidia $(23-) 30-49(-63) \times 10-17(-25) \mu \mathrm{m}$, mostly clavate to sometimes utriform or fusoid, many are septate, hyaline, thin-walled. Caulocystidia 22-57 $\times 6-12 \mu \mathrm{m}$, clavate, in tufts, parallel to stipe hyphae, slightly pale brown. Hymenophoral trama subregular, composed of hyaline, thin-walled hyphae, 5-14(-20.6) $\mu \mathrm{m}$ diam., clamped. Pileus covering composed of a basal layer (subpellis) of prostrate hyphae, 3.5$12 \mu \mathrm{m}$ diam., with slightly incrusted walls; suprapellis polycystodermic, composed of erect chains of globose to subglobose elements, 1247.2(-52) $\times 9-19 \mu \mathrm{m}$, smooth and thin-walled, with yellowish brown pigments. Clamp connections present.

Known distribution - Neotropical: Panamá (Piepenbring 2009), Colombia (Franco-Molano 1999) and Southern Brazil (new record).

Material examined - Brazil, Paraná State, Palotina, PESC, 10 October 2010, leg. AJ Ferreira 16-16 (HCP); 19 October 2011, leg. AJ Ferreira 27-1 (HCP).

Notes - Macrolepiota colombiana is characterized by the presence of a cutis which breaks off in an entire disc or areolae in the center of the pileus and smaller adpressed squamules from center towards the margin, over a smooth or slightly fibrillose ground; microscopically, the cutis is composed of catenulate hyphae, up to $110 \mu \mathrm{m}$ long (FrancoMolano 1999). In general features, the studied specimens agree with the original description, but they have shorter pileus covering hyphae (70-110 $\mu \mathrm{m}$ long) and basidia (44-55 × 12-15 $\mu \mathrm{m})$, according to Franco-Molano (1999). The Northern Hemisphere Macrolepiota procera (Scop.) Singer is closest species, differing from $M$. colombiana by the larger spores (13-17(23) $\times(8.5-) 9-12 \mu \mathrm{m})$ and long cylindrical hyphae $<400 \mu \mathrm{m}$, as well other macroscopic features of pileus (Franco-Molano 1999). Molecular data (Johnson \& Vilgalys 1998, Moncalvo et al. 2002) indicates $M$. procera as the closest relative of $M$. colombiana, as well $M$. gracilenta (Krombh.) Wasser and $M$. excoriata (Schaeff.) Wasser. However, Vellinga et al. (2003), reported that M. procera should be more related to M. dolichaula (Berk. \& Broome) Pegler \& R.W. Rayner, although both taxa are evidently close to M. colombiana. The materials reported from Rio Grande do Sul by Rother (2007) as Macrolepiota procera are distinct from $M$. colombiana because they have larger spores $(17-21 \times 10-11 \mu \mathrm{m})$ and cheilocystidia $(25-34 \times 10-15 \mu \mathrm{m})$ as well as other macroscopic features of pileus and stipe. The studied materials from PESC are the first report of the species from Brazil, however, it is probable that $M$. colombiana has been 
Mycosphere Doi 10.5943/mycosphere/3/6/11
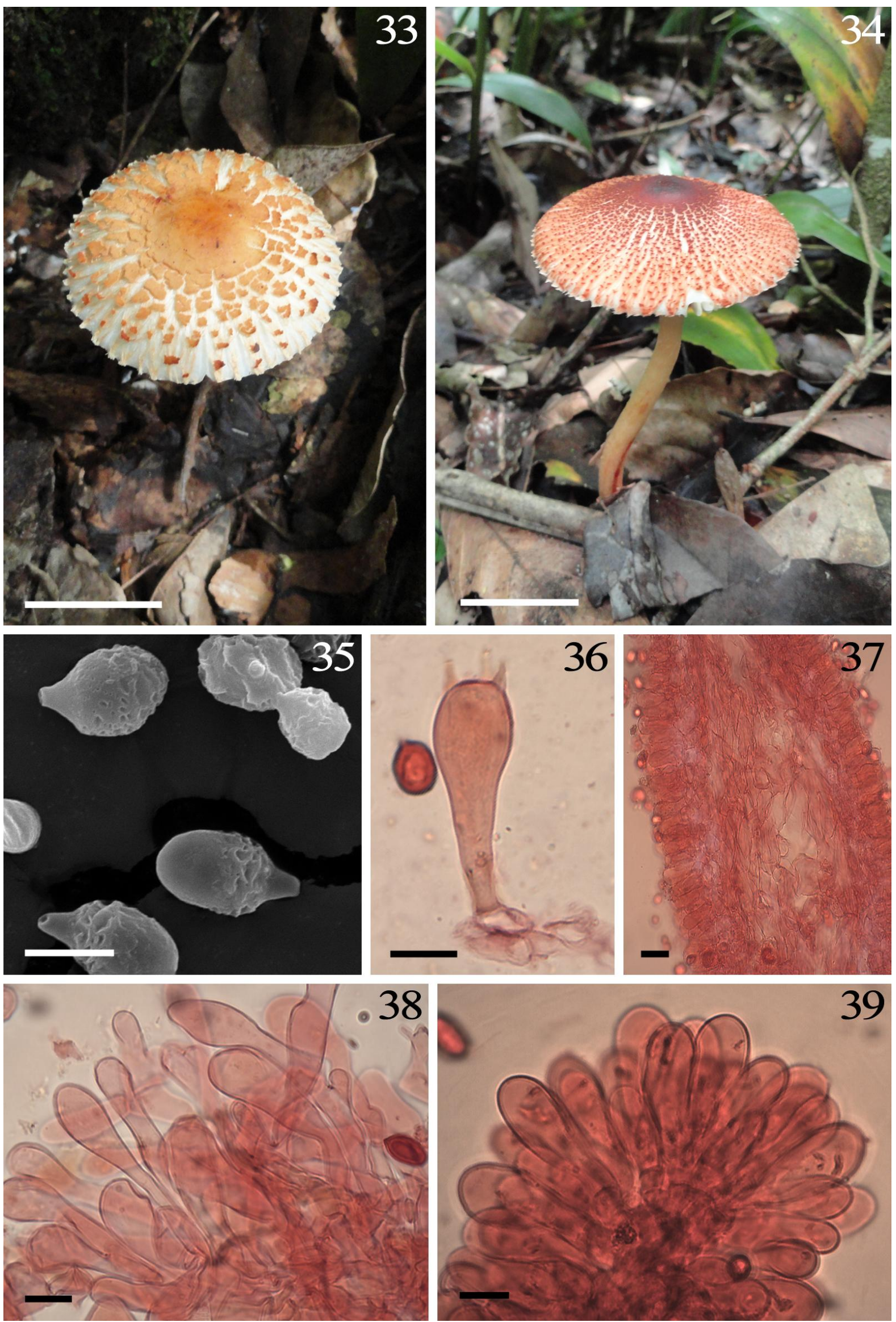

Figs 33-39 - Rugosospora pseudorubiginosa. 33, 34 Basidiomata. 35 Basidiospores under SEM. 36 Basidia. 37 Lamella trama. 38 Pileus covering. 39 Cheilocystidia. - Bars: $\mathbf{3 3}, \mathbf{3 4}=20 \mathrm{~mm} ; \mathbf{3 5}=5$ $\mu \mathrm{m} ; \mathbf{3 6}, \mathbf{3 8}, \mathbf{3 9}=10 \mu \mathrm{m} ; \mathbf{3 7}=20 \mu \mathrm{m}$. 
identified as $M$. procera or another close species or even as Macrolepiota sp. as did Meijer (2010) from Paraná.

Rugosospora pseudorubiginosa (Cifuentes \& Guzmán) Guzmán \& Bandala, Brenesia 32: 108 (1990) Figs 33-39

Basidiomata gregarious, in small groups or solitary, on litter. Pileus $32-52 \mathrm{~mm}$ diam., convex to applanate, slightly umbonate, surface areolate, reddish orange (7A8) to brown (7D8) in the center, then reddish orange (7A6) to greyish red (7B6) and scaly or squamulose towards the margin, which is striate and pinkish white (7A2); context not observed. Lamellae free, close and with lamellulae, margin entire, 3-5 mm diam., yellowish white (4A2), concolour. Stipe 67-130 × 3-5 mm, central, cylindrical to tapered from base to apex, surface fibrillose, greyish orange (6B3) to light orange (6A4), base sub-bulbous, with rhizomorphs. Partial veil forming a membranous apical, upturned and mobile annulus, light orange (6A4). Spore print white (1A1).

Basidiospores 8.4-12.2 × 4.9-7.5 $\mu \mathrm{m}$, $\mathrm{Q}=1.3-2.2, \mathrm{Qm}=1.5$, broad elliptical, ovoid, with a side apiculus, hyaline, walls rugulose and thickened (1.3-2.2 $\mu \mathrm{m})$, without germ pore, dextrinoid and metachromatic. Basidia 24.2-40.2 × 10.1-13.6 $\mu \mathrm{m}$, clavate, tetrasporic, hyaline and thin-walled, with sterigmata 3.2$5.6 \mu \mathrm{m}$. Cheilocystidia 20-36.3 × 10.1-17.3 $\mu \mathrm{m}$, napiform to clavate, hyaline, thin-walled, very numerous in the edges of gills. Pleurocystidia absent. Lamella trama subregular, composed of hyaline hyphae, (1.4)2.8-16 $\mu \mathrm{m}$ diam., thin-walled, clamped. Pileus covering hymeniform, composed of clavate hyphae, sometimes with a long pedicel, and occasionally with a subcapitate apex, 24-66.5 $\times$ 6.8-26.9 $\mu \mathrm{m}$, thin-walled, with intracellular yellowish-brown pigment. Caulocystidia absent.

Known distribution - Neotropical, from México to Southern Brazil (Franco-Molano 1995).

Material examined - Brazil, Paraná State, Palotina, PESC, 10 December 2010, leg. AJ Ferreira 15-2 and 15-11 (HCP); 27 January 2011, leg. AJ Ferreira \& RL Dias 17-40, 17-41 and 17-42 (HCP); 27 April 2011, leg. AJ
Ferreira 23-11 (HCP); 23 April 2012, leg. VG Cortez 34-5 (HCP).

Notes - Rugosospora was proposed by Heinemann (1973) to accommodate lepiotoid agarics with a hymeniform pileus covering composed of clavate to pyriform hyphae, metachromatic basidiospores, rugose to reticulate and without a germ pore, and presence of clamp connections. Two species are known, the Neotropical $R$. pseudorubiginosa and the east African $R$. ochraceobadia (Beeli) Heinem., which differ mostly in the type of ornamentation, which is rugulose in $R$. ochraceobadia (Franco-Molano 1995). This mushroom is known in Brazil from the south and southeast, in the States of Minas Gerais (Rosa \& Capelari 2009), Paraná (Meijer 2006) and Santa Catarina (Franco-Molano 1995).

\section{Acknowledgements}

$\mathrm{CNPq}$ (Brazil) is acknowledged for financial support to the project (Proc. 478373/2010-4) and for scholarship to the first author. Instituto Ambiental do Paraná (IAP) is thanked for allowing fieldwork at PESC (Autorização de Pesquisa Científica 212-10), CME/UFPR is thanked for facilities on SEM analysis. Dr. Felipe Wartchow (Universidade Federal da Paraíba, Brazil) for pre-submission review of the manuscript.

\section{References}

Albuquerque MP, Pereira AB, Carvalho Jr AA. 2010 - A família Agaricaceae Chevall. em trechos de Mata Atlântica da Reserva Biológica do Tinguá, Nova Iguaçu, Rio de Janeiro, Brasil: gêneros Agaricus, Cystolepiota e Lepiota. Acta Botanica Brasilica 24, 497-509.

Candusso M, Lanzoni G. 1990 - Lepiota s.l. Fungi Europei 4. Saronno, Giovanna Bella.

Capelari M, Gimenes LJ. 2004 Leucocoprinus brunneoluteus, uma nova espécie de Agaricaceae. Hoehnea 31, 331-335.

Capelari M, Maziero R. 1988 - Fungos macroscópicos do estado de Rondônia região dos Rios Jaru e Ji-Paraná. Hoehnea 15, 28-36. 
Dennis RWG. 1961 - Fungi venezuelani. IV. Agaricales. Kew Bulletin 15, 67-156.

Didukh MY, Wasser SP, Nevo E. 2003 Medicinal value of species of the family Agaricaceae Cohn (higher Basidiomycetes): current stage of knowledge and future perspectives. International Journal of Medicinal Mushrooms 5, 133-152.

Franco-Molano AE. 1995 - Observations on Rugosospora Heinemann in the Neotropics. Mycologia 87, 574-578.

Franco-Molano AE. 1999 - A new species of Macrolepiota from Colombia. Actualidades Biológicas 21, 13-17.

Franco-Molano AE, Aldana-Gómez R, Halling RE. 2000 - Setas de Colombia (Agaricales, Boletales y otros hongos). Medellín, Universidad de Antioquia.

Gubitz C. 2011 - Eine mykofloristische Bestandsaufnahme in den Gewächshäusen des ÖkologischBotanischen Gartens der Universität Bayereuth - Teil 1. Zeitschrift für Mykologie 77, 203 - 242.

Heinemann P. $1973-$ Leucocoprineés nouvelles d'Afrique Centrale II. Bulletin du Jardin Botanique Belgique 43, 7-13.

Holec J, Hálek V. 2008 - Record of the rare greenhouse fungus Lepiota elaiophylla (Agaricales, Agaricaceae) in Prague, Czech Republic, with notes on its taxonomy and distribution. Mycotaxon 105, 433-439.

IAP - Instituto Ambiental do Paraná. 2006 Plano de Manejo do Parque Estadual de São Camilo. http://www.uc.pr.gov.br/modules/conte udo/conteudo.php? conteudo $=25$.

Johnson J, Vilgalys R. 1998 - Phylogenetic systematics of Lepiota sensu lato based on nuclear large subunit rDNA evidence. Mycologia 90, 971-979.

Kirk PM, Cannon PF, Minter DW, Stalpers JA. 2008 - Dictionary of the Fungi, $10^{\text {th }}$ ed. Wallingford, CABI.

Kornerup A, Wanscher JH. 1978 - Methuen Handbook of Colour. $3^{\text {rd }}$ ed. London, Eyre Methuen.

Kumar TKA, Manimohan P. 2009 - The genera Leucoagaricus and Leucoco- prinus (Agaricales, Basidiomycota) in Kerala State, India. Mycotaxon 108, 385-428.

Largent DL. 1977 - How to Identify Mushrooms to Genus. I. Macroscopic Features. Eureka, Eureka Publ.

Largent DL, Johnson D, Watling R. 1986 How to Identify Mushrooms to Genus. III. Microscopic Features. Eureka, Eureka Publ.

Meijer AAR. 2006 - Preliminary list of the macromycetes from the Brazilian state of Paraná. Boletim do Museu Botânico Municipal (Curitiba) 68: 1-55.

Meijer AAR. 2010 - Preliminary list of the macromycetes from the Brazilian state of Paraná: corrections and updating. Boletim do Museu Botânico Municipal (Curitiba) 72: 1-9.

Moncalvo JM, Vilgalys R, Redhead SA, Johnson JE, James TY, Aime MC, Hofstetter V, Verduin SJW, Larsson E, Baroni TJ, Thorn RG, Jacobsson S, Clémençon H, Miller OK Jr. 2002 One hundred and seventeen clades of euagarics. Molecular Phylogenetics and Evolution 23, 357-400.

Murrill WA. 1912 - The Agaricaceae of the Pacific coast-II. Mycologia 4, 231-262.

Pegler DN. 1983 - Agaric flora of the Lesser Antilles. Kew Bulletin Additional Series 9, 1-668.

Piepenbring M. 2009 - Reportes nuevos de Agaricales para Panamá. Acta Biologica Panamensis 1, 22-38.

Rosa LH, Capelari M. 2009 - Agaricales fungi from Atlantic rain forest fragments in Minas Gerais, Brazil. Brazilian Journal of Microbiology 40, 846-851.

Rother MS. 2007 - Espécies de Agaricaceae Chevall. (Agaricales, Basidiomycota) no Parque Estadual de Itapuã, Viamão, Rio Grande do Sul. Porto Alegre, Universidade Federal do Rio Grande do Sul, MSc. Dissertation.

Rother MS, Silveira RMB. 2008 - Família Agaricaceae (Agaricales, Basidiomycota) no Parque Estadual de Itapuã, Viamão, Rio Grande do Sul, Brasil. Revista Brasileira de Biociências 6, 259-268.

Rother MS, Silveira RMB. 2009a - 
Leucoagaricus lilaceus (Agaricaceae), a poorly known Neotropical agaric. Mycotaxon 107, 473-481.

Rother MS, Silveira RMB. 2009b Leucocoprinus Pat. (Agaricaceae) no Parque Estadual de Itapuã, Viamão, RS, Brasil. Acta Botanica Brasilica 237, 720-728.

Singer R. 1973 - Diagnoses fungorum novorum Agaricalium III. Beiheft zur Sydowia 7, 1-106.

Singer R, Digilio APL. 1951 - Pródromo de la flora agaricina Argentina. Lilloa 25, 5461.

Sobestiansky G. 2005 - Contribution to a macromycete survey of the States of Rio Grande do Sul and Santa Catarina in Brazil. Brazilian Archives of Biology and Technology 48, 437-457.

Sysouphanthong P, Hyde KD, Chukeatirote E, Vellinga EC. 2011 - A review of genus Lepiota and its distribution in Asia. Current Research in Environmental \& Applied Mycology 1, 161-176.

Vellinga EC. 2001a - Leucocoprinus. In Flora Agaricina Neerlandica: critical monographs on families of agarics and boleti occurring in the Netherlands (eds
ME Noordeloos, THW Kuyper, EC Vellinga). A.A. Balkema Publishers, Rotterdam, 5: 76-84.

Vellinga EC. 2001b - Studies in Lepiota III. Some species from California, USA. Mycotaxon 80, 285-295.

Vellinga EC. 2003 - Phylogeny of Lepiota (Agaricaceae) - Evidence from nrITS and nrLSU sequences. Mycological Progress 2, 305-322.

Vellinga EC. 2004 - Genera in the family Agaricaceae: evidence from nrITS and nrLSU sequences. Mycological Research 108, 354-377.

Vellinga EC, Huijser HA. 1997. Lepiota xanthophylla and its greenhouse counterpart. Bolletino del Gruppo Micologico G. Bresadola - Nuova Serie 40, 457-464.

Vellinga EC, de Kok RPJ, Bruns TD. 2003 Phylogeny and taxonomy of Macrolepiota (Agaricaceae). Mycologia 95: 442-456.

Wartchow F, Putzke J, Cavalcanti MAQ. 2008 - Agaricaceae Fr. (Agaricales, Basidiomycota) from areas of Atlantic forest in Pernambuco, Brazil. Acta Botanica Brasilica 22, 287-299. 